\title{
Histoplasma capsulatum var. capsulatum Darling
}

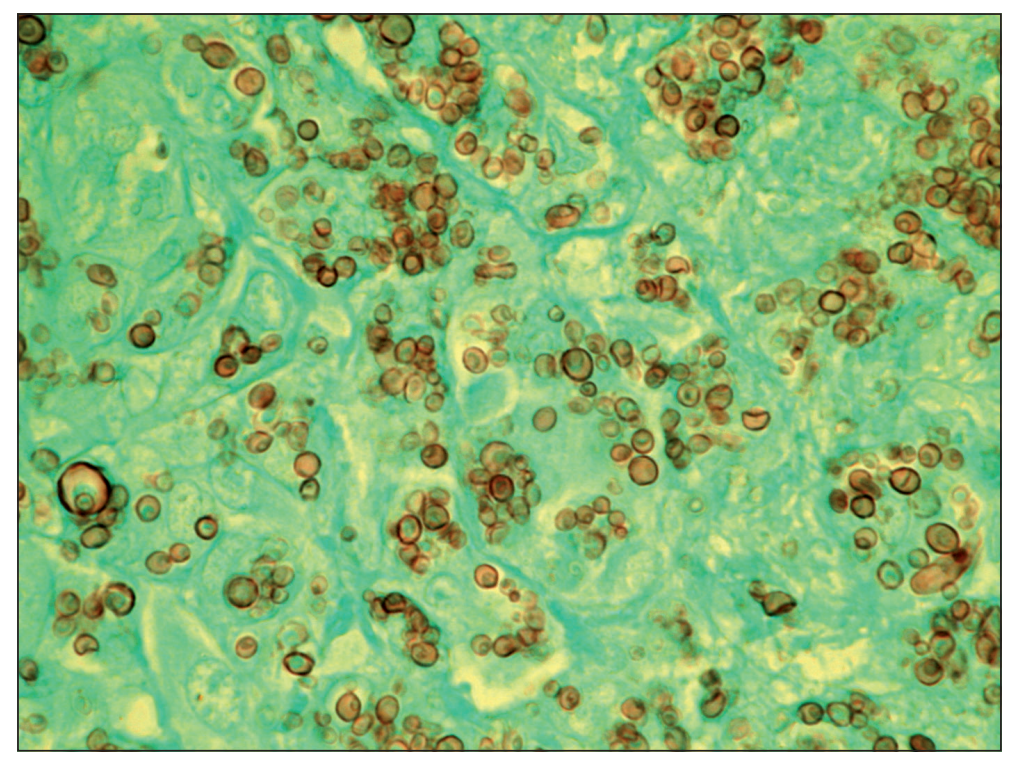

Figura 1. Formas levaduriformes en biopsia de piel de paciente con histoplasmosis diseminada. Tinción Gomori-Grocott. 100X.

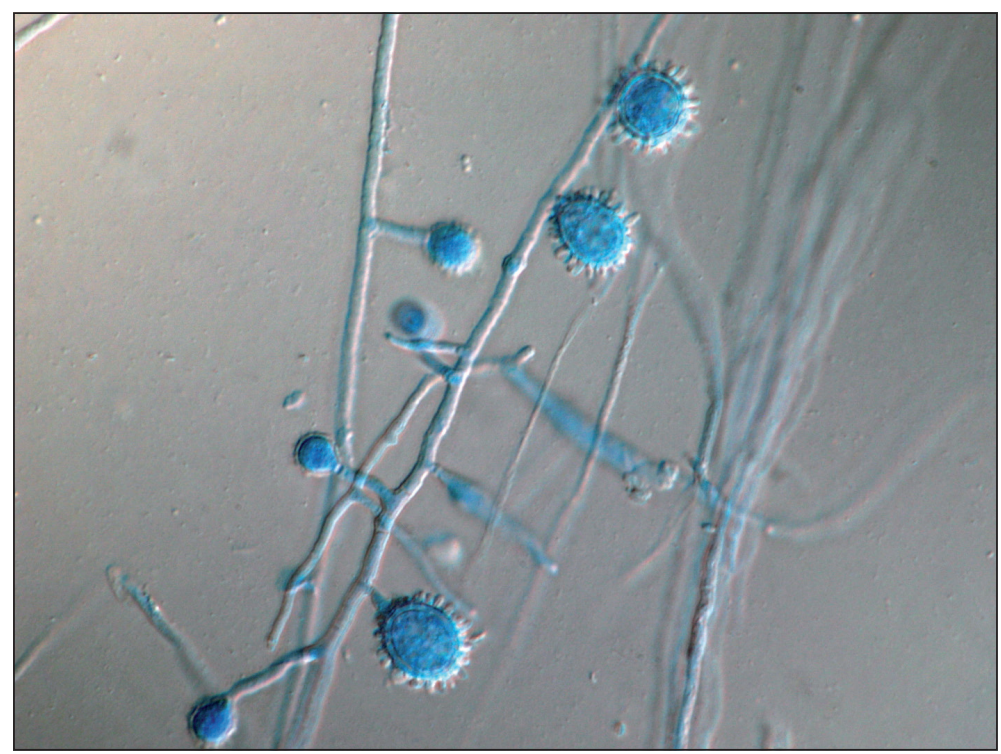

Figura 2. Macroaleuroconidios de colonia cultivada a $27{ }^{\circ} \mathrm{C}$ por 10 días. Tinción de lactofenol con azul de algodón. 100X. 


\section{Histoplasma capsulatum var. capsulatum Darling}

Histoplasma capsulatum var capsulatum Darling es un hongo dimórfico, filamentoso a temperaturas inferiores a $30^{\circ} \mathrm{C}$, pero en las células de los mamíferos o en medios especiales a $35-37^{\circ} \mathrm{C}$ crece como una levadura (Figura 1). Se encuentra ampliamente distribuido en la naturaleza, en especial en suelos húmedos, ácidos, con alto contenido de nitrógeno y con excrementos de murciélagos o pájaros. Es endémico en algunos países de Centroamérica (Puerto Rico, El Salvador, Costa Rica y República Dominicana), Sudamérica (Venezuela, Ecuador, Brasil, Paraguay, Uruguay y Argentina), Sudeste Asiático, África y algunas áreas de Europa. Sus otras variedades son H. capsulatum var. duboisii, descrito principalmente en África e H. capsulatum var farciminosum, aislado en el Mediterráneo, África y Asia, el cual produce linfangitis epizootica en caballos y mulas.

En Chile, la mayoría de los casos confirmados han sido personas que han viajado a zonas endémicas donde la concentración del agente es alta, ya sea en el suelo o en el aire, tales como cuevas, galerías, minas o los diversos lugares donde anidan murciélagos.

Los casos de histoplasmosis pulmonar aguda en general son asintomáticos y sin alteraciones radiológicas, sin embargo, aproximadamente $10 \%$ puede tener síntomas generales y/o respiratorios, además del riesgo de diseminación o de cronicidad por reactivación posterior (meses o años) de agentes viables presentes en diversos parénquimas.

La identificación se basa en el aislamiento del agente desde muestras clínicas mediante el cultivo en medios enriquecidos como agar cerebro corazón, agar sangre o agar chocolate, los que permiten el desarrollo de ambas fases, levaduriforme y filamentosa dependiendo de la temperaturas de incubación. También puede usarse agar al 2\% de glucosa $+1 \%$ de extracto de levadura, agar papa dextrosa + cisteína o agar Sabouraud. Es conocida la lentitud de crecimiento de esta especie, situación que debe considerarse para no eliminar los cultivos antes de las 4 semanas. En los cultivos mencionados se puede obtener la morfología característica de las colonias y los patrones de esporulación que permitan demostrar las características macroconidias tuberculadas de la fase asexual de esta especie (Figura 2).

\section{Referencias bibliográficas}

1.- Guimaraes A J, Nosanchuk J D, Zancopé-Oliveira R M. Diagnosis of histoplasmosis. Braz J Microbiol 2006 ; 37 : 1-13.

2.- Kasuga T, Taylor J W, White T J. Phylogenetic relationships of varieties and geographical group of the human pathogenic fungus Histoplasma capsulatum Darling. J Clin Microbiol 1999; 37: 653-63.

Rodrigo Cruz Laboratorio de Micología Universidad de Valparaiso 